Revue des patrimoines

6 | 2005

Patrimoine en situation : l'Inventaire général entre histoire et prospective

\title{
Les choses...
}

Pierre Curie et Laurence de Finance

\section{(2) OpenEdition \\ Journals}

Édition électronique

URL : http://journals.openedition.org/insitu/8868

DOI : $10.4000 /$ insitu.8868

ISSN : 1630-7305

Éditeur

Ministère de la culture

Référence électronique

Pierre Curie et Laurence de Finance, «Les choses... », In Situ [En ligne], 6 | 2005, mis en ligne le 15 mai 2012, consulté le 20 avril 2019. URL : http://journals.openedition.org/insitu/8868 ; DOI : 10.4000/ insitu. 8868

Ce document a été généré automatiquement le 20 avril 2019

\section{(c) (i) () $\Theta$}

In Situ Revues des patrimoines est mis à disposition selon les termes de la licence Creative Commons Attribution - Pas d'Utilisation Commerciale - Pas de Modification 4.0 International. 


\title{
Les choses...
}

\author{
Pierre Curie et Laurence de Finance
}

1 Le rapport contenant/contenu, aujourd'hui encore déterminant dans la structure des notices électroniques de l'Inventaire, dénote une habitude mentale qui subordonne logiquement le mobilier au bâti, le lui annexe d'une certaine façon, notamment dans l'organisation des données. Organiquement, l'observation accrédite cette conception et l'Inventaire général, du moins dans ses programmes topographiques complets, a toujours tenu à assujettir l'un à l'autre, proposant de cette façon une vision globale du patrimoine.

2 Mobile par essence, l'objet est voué à des déplacements susceptibles d'entrâner des pertes, des vols, des adultérations liées aux changements de fonction; ainsi les chercheurs de l'Inventaire constatent-ils quotidiennement que sur le terrain, en réalité, la liaison de l'objet et de l'architecture ne va pas toujours de soi : c'est un calice ancien trouvé dans une église moderne, c'est un tableau du XIX siècle déposé dans une chapelle romane, des vitraux médiévaux aux baies d'une église des années trente, un retable déplacé, un tombeau partiellement remployé comme autel... Ces avatars semblent barbares aux amateurs puristes, mais en tenant compte du temps qu'il a fallu pour constituer ces collections disparates, des changements du goût et des fluctuations pécuniaires qui ont conduit à tel ou tel décor, tel ou tel don, on comprend que l'on ne peut guère aborder le mobilier d'une église - ou même celui d'une mairie ou d'un hôpital sans un sens de la relativité nuancé d'historicité. Car en effet cette hétérogénéité même a une explication, un sens, qui ne peuvent se dégager du long chaos indistinct des séquences historiques, sur un territoire donné, que par la perception du chercheur ; à lui de la souligner dans sa sélection et son travail scientifique.

Depuis quarante ans, les chercheurs de l'Inventaire recensent des objets, de la fameuse petite cuillère, élément basique d'après la tradition du service, jusqu'aux plus prestigieux tableaux ou sculptures. Ils ont apporté à la communauté scientifique des ethnologues et des historiens de l'art une quantité considérable d'éléments (environ 170000 dossiers Inventaire dans la base Palissy en 2005) dont quelques chefs-d'œuvre ignorés. Ils ont très largement réécrit des pans entiers de la connaissance dans des domaines extrêmement 
variés (liturgie, orfèvrerie, arts dits «populaires »...) et pourtant, ces avancées sont à peine reconnues ; pourquoi?

4 La faute en revient certainement à un primat que les Français accordent à l'architecture : il est peu de sculpture publique qui ait déclenché récemment une aussi forte polémique que celle suscitée, par exemple, par la pyramide du Louvre (qui se souvient de Clara Clara de Richard Serra [1984] ?) Les enjeux financiers impliqués par la construction ou la restauration du bâti apparaissent encore aujourd'hui comme les plus importants, or il n'est pas inopportun - même si c'est un peu vulgaire - de rappeler ici qu'un beau Rubens, aujourd'hui, vaut 79 millions d'euros sur le marché international, c'est-à-dire l'équivalent de bien des années de travaux sur une cathédrale.

Une autre difficulté dans l'analyse des objets est celle de la spécialisation des chercheurs, car il est présomptueux de croire possible une compétence globale dans ce qui est beaucoup plus qu'un simple domaine, quand sont concernés une infinité de types d'œuvres, de matériaux et de techniques, alors que l'architecture constitue en soi un objet beaucoup plus cohérent. D'autre part, cette multiplicité kaléidoscopique correspond à des sensibilités assez variées : on peut relier conceptuellement les arts de la peinture, du vitrail, de la tapisserie et de la sculpture, qui sont traditionnellement ceux de l'image, alors que le meuble, l'orfèvrerie, le textile, le verre ou la céramique font appel à des compétences d'un autre ordre, à des approches d'un autre niveau (connaissance des usages, des techniques, etc.). Certes, avec ses Vocabulaires, l'Inventaire s'est depuis longtemps donné des outils tant pour recenser les typologies (le mobilier, les objets domestiques ou ceux du culte catholique...) que pour étudier les techniques (la tapisserie, la sculpture, le métal, la céramique...). En outre, dans le champ de l'image religieuse, un outil multimédia est en cours d'expérimentation, qui répondra au besoin de précision de la lecture iconographique comme à l'analyse formelle des sources gravées, notamment pour l'identification des modèles et de leurs copies. Mais il reste beaucoup à faire, même si demain, avec des ouvrages sur les véhicules hippomobiles, sur la peinture, ou aprèsdemain sur l'ornement, sur les instruments de musique et pourquoi pas la gravure ou la photographie, l'Inventaire général continue de travailler sur les principes de l'analyse de sujets toujours nouveaux. L'élargissement du champ d'étude donne aux ustensiles de la vie quotidienne, aux instruments de mesure (fig. $n^{\circ} \mathbf{1}$ ) ou aux outils de l'industrie les plus modestes un statut d'objets inventoriés qui les qualifie dans une nomenclature définie: peut-être les prochaines générations les regarderont-elles comme des témoins de notre civilisation, comme l'archéologue perçoit aujourd'hui les silex taillés ou les tessères romaines. Et bien que cette contribution à l'histoire de l'art, par les Vocabulaires, soit perçue par certains comme une intrusion, elle finit par constituer un apport méthodologique dont lui savent gré la très grande majorité des chercheurs et des étudiants. De plus, ces publications, traditionnelles mais très théorisées, peuvent aussi servir de socle aux forums internationaux, à l'heure des métalangages et des recherches multilingues par les réseaux de communication. 


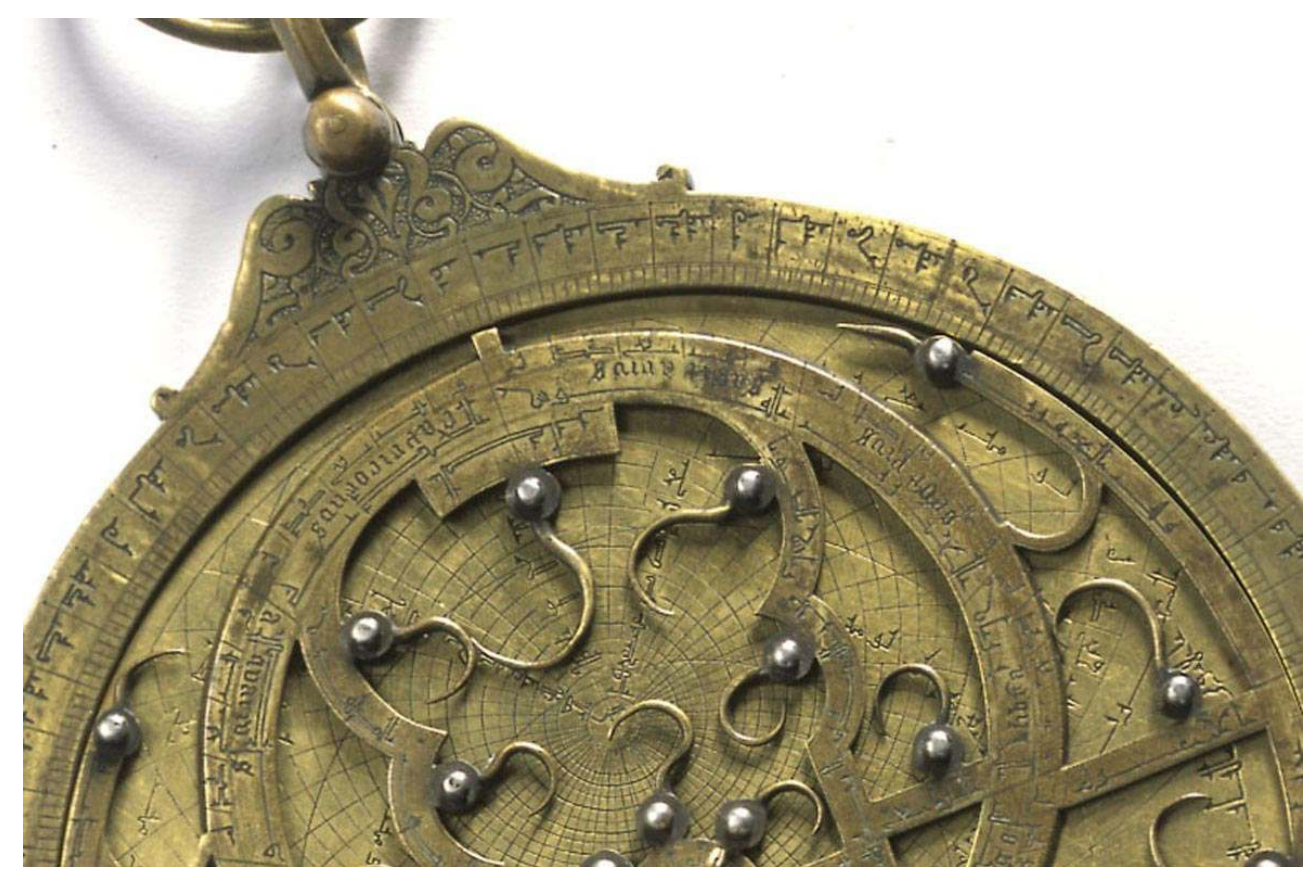

Détail de l'astrolabe stéréographique septentrional signé et daté en arabe coufique : fait par Abû Bakr Ibn Yûsuf en la ville de Marrakech que Dieu la rende prospère l'année 605 [1208 - 1209 de l'ère chrétienne]. Cet astrolabe conservé au sein de l'observatoire de Strasbourg (Université Louis Pasteur) a été étudié dans le cadre du protocole d'inventaire du patrimoine astronomique signé entre les ministères de la culture et de la recherche

Phot. Inv. C. Menninger (C) Inventaire général, ADAGP, 2003

6 Par ailleurs, le problème de la sélection est depuis toujours au centre des débats, car un inventaire scientifique est un filtre plus qu'un listage, adapté au cadre topographique déterminé par le type d'étude. L'objet, grand chef-d'œuvre de l'art ou modeste témoignage ethnologique, s'il a bien toute sa place dans le contexte local, n'acquiert son plein sens que dans un champ d'étude et un domaine de définition plus vastes. Examinons telle copie de l'Assomption de Murillo dans l'église d'un petit village : en dehors du sujet, support de la dévotion, nulle considération artistique n'y justifie sa présence. Regardonsla, au contraire, d'un peu plus haut, dans le contexte français de l'hispanophilie au XIX ${ }^{e}$ siècle, de la galerie espagnole de Louis-Philippe au Louvre, des envois de l'Etat consignés dans la série $\mathrm{F}^{21}$ des Archives Nationales, forme de système avant la lettre de subvention aux artistes et expression d'une volonté éducative, et elle apparaît alors comme l'élément d'une chaîne dont la valeur historique n'est évaluable que dans le cadre d'une production en grande série, à l'échelon national. Et comme pour toute chaîne, la valeur de chaque maillon est unique et son intégrité précieuse... La notion de " qualité » a-t-elle elle-même plus de sens, comme critère de sélection, puisque tout est relatif et subjectif et que le banal ici est exceptionnel là ? Finalement, il faut bien s'y résoudre, c'est le chercheur qui tranche, par sa culture, sa sensibilité et la somme de toutes ses expériences qui objectivent la sélection et son corollaire, l'élimination.

Parallèlement, il est nécessaire de comprendre la différence de base entre un inventaire de gestion, qui énumère simplement les choses, qui les dénombre sans les étudier, et un inventaire de recherche, qui analyse très précisément ses items et dont la finalité n'est pas seulement l'appréhension du patrimoine à l'échelon local, mais sa compréhension à 
des échelles variables et des niveaux plus vastes. Le premier peut être un outil et un produit utile à la promotion du tourisme ou à l'assurance des œuvres - certaines communes y pensent -, le second construit véritablement un système intellectuel ouvert et en mutation permanente ou, pour citer André Malraux, une « recherche, devenue son objet propre, [qui] fait de l'art une valeur à découvrir, l'objet d'une question fondamentale.» Or le but de l'Inventaire, faut-il le rappeler, est de constituer une documentation complète et accessible, c'est-à-dire digne d'un service public. Pour répondre à cette attente, divers sites documentaires offrant des synthèses nationales sont déjà consultables sur le site Internet du ministère de la culture, où ils sont constamment enrichis. Des catalogues illustrés d'œuvres datées, constitués par catégorie technique, présentent l'évolution formelle, stylistique et technique de plusieurs types d'objets récurrents dans les études d'inventaire. Le premier d'entre eux concerne les autels, récemment complété par celui des calices, objets d'orfèvrerie indispensables à la célébration du culte catholique dont plus de 8000 , conservés dans les sacristies, ont été étudiés ${ }^{1}$. Ils seront augmentés à l'automne 2005 du catalogue des fonts baptismaux et, plus tard, de ceux des vitraux civils puis des textiles datés. Constitués à partir de l'abondante documentation réunie en région, ces catalogues ont l'ambition d'offrir une synthèse nationale tout en mettant en lumière des particularités régionales. Grâce aux œuvres référencées et bien documentées, des répertoires d'artistes, également consultables en ligne, sont mis en place : celui des orfèvres parisiens postérieurs à 1875 regroupe 3000 noms d'artistes auprès desquels devraient bientôt figurer leurs poinçons ${ }^{2}$ et celui des peintres verriers dont le corpus a été bien enrichi depuis sa première parution, il y a 20 ans, dans la Revue de l'Art ${ }^{3}$. Ces sites d'information et de connaissance sont des outils de la recherche actuelle, ils en deviendront les véritables moteurs, demain, quand les illustrations et les liens avec les œuvres référencées dans les bases nationales (Mérimée, Palissy) seront opérationnels.

8 L'avantage d'offrir librement une documentation nationale considérable n'est plus à démontrer. Dans une optique très ambitieuse, l'Inventaire a tenté autrefois d'analyser le meuble ou l'objet dans sa technique comme dans sa structure, escomptant qu'une nouvelle approche, moins fondée sur l'analyse esthétique que sur des données factuelles positives, renouvellerait la connaissance de tel ou tel domaine. Quarante années plus tard, on sait aujourd'hui que ce décorticage minutieux n'a pas donné, globalement, les résultats souhaités, et qu'il a sans doute ralenti les opérations d'étude et d'archivage des informations. Cependant, il a permis d'aborder et de voir toutes sortes de phénomènes peu pris en compte auparavant : en inventant une approche critique de l'objet, avec ses matériaux et leur mise en œuvre, avec une étude précise des accidents, des altérations et des réfections, l'Inventaire a été à l'origine d'une approche véritablement archéologique du domaine. En admettant enfin que l'objet mobilier, comme un édifice, subissait des métamorphoses dans le temps, il en a proposé une lecture plus riche qui mettait en évidence les remaniements, les restaurations subies ou les changements structurels ou formels, et qui pointait là le mouvement même de la vie des choses, qui est aussi celui des hommes qui les fabriquent et les utilisent. 


\section{NOTES}

1. Voir le site : http://www.culture.gouv.fr/culture/inventai/presenta/calices/calice-index.htm.

2. Voir le site : http://www.culture.gouv.fr/documentation/marque/orfeo-frame.htm.

3. Callias Bey, M., Chausse, V., de Finance, L., Gatouillat, F. Enquête sur les peintres verriers ayant travaillé en France au XIX ${ }^{\mathrm{e}}$ siècle. Revue de l'Art, 1986, n 72, p. 67-90. L'enquête étant étendue aux artistes du XX siècle, le corpus initial (725 noms publiés) a aujourd'hui doublé.

\section{RÉSUMÉS}

Dans la culture tant des Monuments historiques que de l'Université française, le monumental a longtemps prévalu sur l'objet, peinture, sculpture ou objet d'art qui, lui, dans l'inconscient collectif, relevait tout naturellement du musée. Dans la pensée et dans les goûts d'André Chastel, les catégories n'étaient pas aussi manichéennes et à l'Inventaire, malgré une certaine prééminence de l'architecture, l'objet - au sens large - tint, dès le début de l'aventure, une place non négligeable. Le premier des Vocabulaires parus, en 1969, fut consacré à la tapisserie, suivi, en une vingtaine d'années, par la sculpture, les objets et le mobilier civil domestique, le vitrail...

In the culture of France's historic monuments, as in French universities, the monumental has long been considered as more important than sculptures or works of art, generally seen as more to do with museums. In the writings and tastes of André Chastel, however, the categories were not so clear-cut and, at the French Inventory, although architecture has enjoyed a certain preeminence, the object, in the broadest sense of the term, has been taken into consideration form the outset. Over 17,000 items now feature in the national database Palissy, on moveable objects. The first scientific vocabulary, published by the Inventory services in 1969, was devoted to tapestry and, over the last twenty years, other vocabularies have dealt with sculpture, domestic civil furniture and stained glass.

\section{INDEX}

Keywords : France, furniture, inventory, tapestry, work of art

Mots-clés : autel, catalogue, céramique, documentation, font baptismal, hippomobile, iconographie, instrument de musique, inventaire, Malraux, métal, mobilier, objet sculpture, orfèvre, orfèvrerie, ornement, peintre verrier, photographie peinture, recherche, restauration, tapisserie, textile, verre, vitrail, vocabulaire 


\section{AUTEURS}

\section{PIERRE CURIE}

Conservateur du patrimoine. Sous-direction de l'archéologie, de l'ethnologie, de l'inventaire et du système d'information. pierre.curie@culture.gouv.fr

\section{LAURENCE DE FINANCE}

Conservatrice du patrimoine. Sous-direction de l'archéologie, de l'ethnologie, de l'inventaire et du système d'information. laurence.de-finance@culture.gouv.fr 